\title{
Inadvertent urinary catheter placement in the ureter: A report on two cases and a literature review
}

\section{Cateterismo ureteral iatrogeno: a propósito de dos casos y revisión de la literatura}

\footnotetext{
iDDaniel Hijazo-Gascón, ${ }^{1 *}$ iDFrancisco Xavier Elizalde-Benito, ${ }^{1}$ iDIgnacio Quintana-Martínez, ${ }^{1}$ iD Laura Muñiz-Suárez, ${ }^{1}$ iD Agustín Asensio-Matas, ${ }^{1}$ Paula Gayarre-Abril, ${ }^{1}$ iDAna Pilar Huertas-Harguindey. ${ }^{1}$
}

Keywords:

Iatrogenic, Bladder catheterization, Ureteral trauma, Case report.

\section{Abstract}

Background: Bladder catheterization is one of the most frequent procedures in Urology, but it is not exempt from complications.

Relevance: Unintentional Foley catheter placement in the ureter is a rare occurrence that can produce serious complications. Few cases are described in the literature.

Case report: We present herein two cases of inadvertent Foley catheter balloon inflation in the ureter. Case 1: an 85-year-old-patient with an indwelling Foley catheter was admitted to our emergency department due to abdominal pain in the hypogastrium, dysuria, and diagnosis of septic shock from extended-spectrum beta-lactamase-producing Escherichia coli. Case 2: a 75-year-old patient underwent transurethral resection of the bladder and presented with persistent hematuria and abdominal pain in the postoperative period.

Conclusion: Unintentional urinary catheter placement in the ureter is an unusual complication and a diagnostic challenge that should be suspected in the presence of abdominal pain after bladder catheterization.

Citación: Hijazo-Gascón D., Elizalde-Benito F. X., Quintana-Martínez I., Muñiz-Suárez L., Asensio-Matas A., Gayarre-Abril P., et al. Inadvertent urinary catheter placement in the ureter: A report on two cases and a literature review. Rev. Mex. Urol. 2020;80(1):pp1-5

Correpondencia: *Daniel Hijazo-Gascón. Avda. San Juan Bosco, 15, 50009 Zaragoza, Spain. Email: danielhijazo@hotmail.com
Recepción: 06 de diciembre de 2019 Aceptación: 29 de febrero de 2020
${ }^{1}$ Universidad de Zaragoza, Hospital Clínico Universitario Lozano Blesa, Zaragoza, Spain.

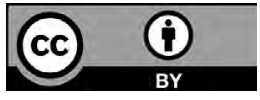




\section{Background}

Bladder catheterization, either with a urethral catheter or a supra-pubic catheter, is one of the most common clinical procedures performed in Urology. Nonetheless, it is not exempt from complications. ${ }^{(1)}$ An indwelling catheter should only be placed when it is clearly indicated and should not be retained longer than necessary. Alternatives to placing an indwelling catheter should first be considered, making it a last resort when other options have failed or proved to be insufficient. ${ }^{(2)}$ Inadvertent placement of the urinary catheter in the ureter is a rare complication that can lead to serious complications, such as ureteric obstruction with hydronephrosis, ureteric injury, or even ureteric rupture. ${ }^{(3)}$ We present herein two cases of unintentional Foley catheter balloon inflation in the ureter. Only 23 other cases have been reported, 16 of which were related to bladder catheterization. ${ }^{(3)}$

The aim of the present article was to describe two such cases seen at our healthcare institution, to review the literature, and to aid in the diagnosis of inadvertent urinary catheter placement in the ureter.

\section{Case report}

An 85-year-old patient had a past medical history of high blood pressure and chronic obstructive pulmonary disease, as well as long-term indwelling urethral catheters due to urinary retention and voiding dysfunction, most likely secondary to myasthenia gravis. The patient was admitted to our emergency department because of abdominal pain in the hypogastrium, dysuria, and the diagnosis of septic shock from extended-spectrum beta-lactamase-producing Escherichia coli after Foley catheter replacement. The patient had poor progression, presenting with persistent pain, despite analgesic treatment, and oligoanuria. Urgent ultrasound identified the absence of the Foley catheter balloon in the bladder. Abdominal-pelvic computed tomography (CT) revealed a Foley catheter at the right ureter (Images 1 and 2). The bladder catheter was replaced without incident. Patient progression was good, after antibiotic treatment, with no incidents resulting from later indwelling Foley catheter replacements.

Image 1: Case 1, Coronal CT image showing Foley catheter at the right ureter

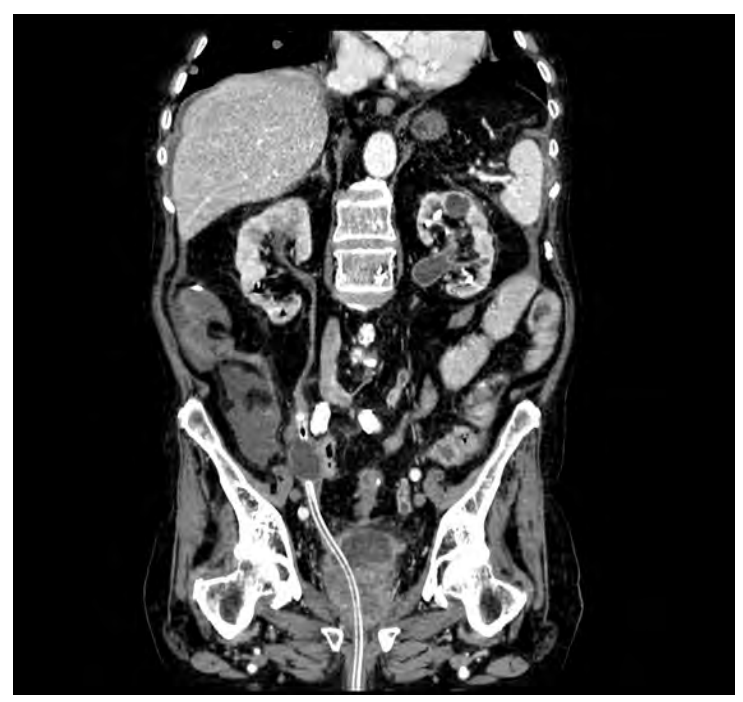


Image 2: Case 1, Sagittal CT image showing Foley catheter at the right ureter

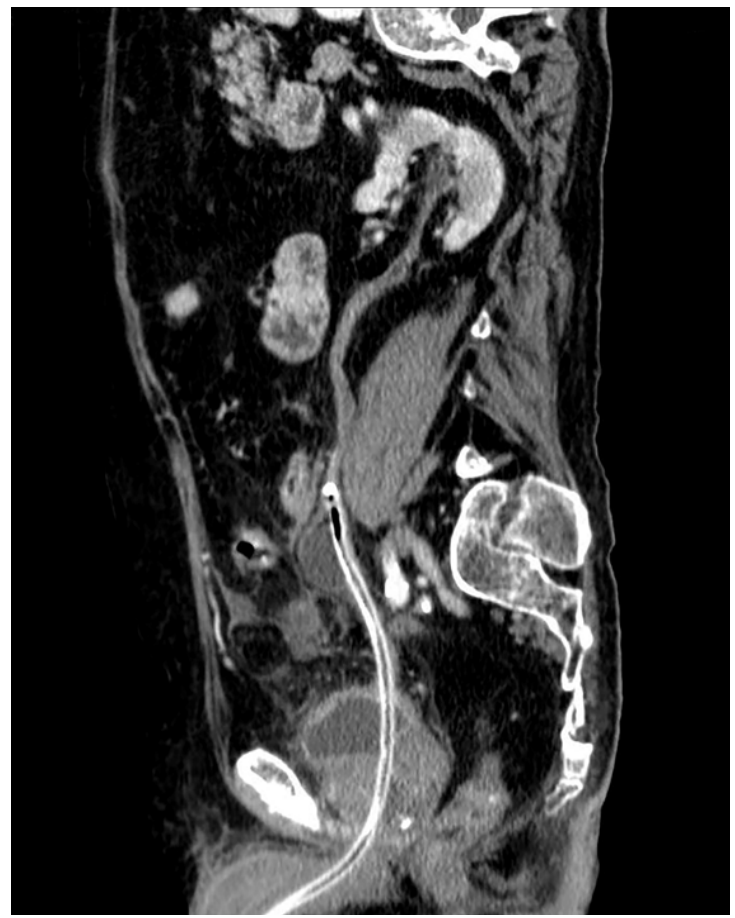

A 75-year-old patient had a past medical history of high blood pressure, atrial fibrillation, mitral insufficiency, chronic obstructive pulmonary disease, and T1GII urothelial bladder carcinoma and was admitted to our department due to hematuria and anemia. Transurethral resection of the bladder (TURB) was performed and bilateral ureteral reflux and bilateral hydroureteronephrosis were diagnosed. The patient presented with persistent hematuria and abdominal pain in the postoperative period. Abdominal and pelvic CT identified a Foley catheter at the right ureter (Images 3 and 4). It was removed and replaced with no incidences and the patient's postoperative progression was good.
Image 3: Case 2, Coronal CT image showing Foley catheter at the right ureter

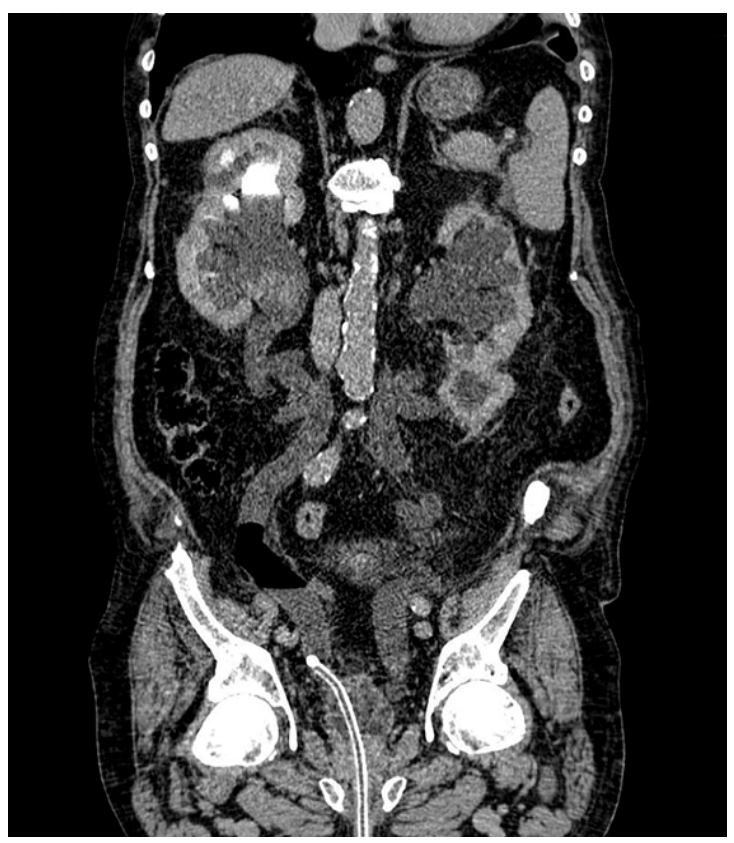

Image 4: Case 2, Sagittal CT image showing Foley catheter at the right ureter

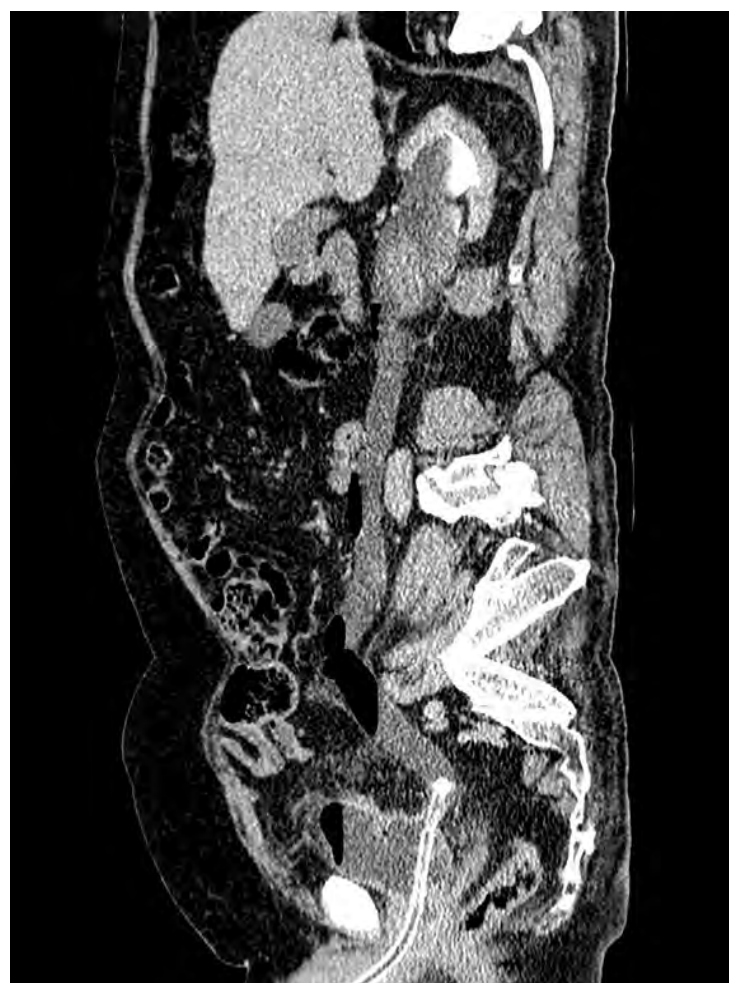




\section{Cateterismo ureteral iatrogeno: a propósito de dos casos y revisión de la literatura. Hijazo-Gascón D., et al.}

\section{Discussion}

Patient catheterization can be difficult for a variety of reasons. Medical advice and support should be sought if problems occur during or after catheter insertion. Catheter-related complications include urinary tract infection, trauma and inflammatory reactions, urethral stricture, bladder stones, hypospadias, false route, and possible bladder carcinoma and can result in one or more of the following symptoms: pain, bypassing, blockage, catheter expulsion, and bleeding. ${ }^{(1)}$ The removal of both urethral and suprapubic catheters is frequently painful, which is often a consequence of ridge formation on the catheter balloon. ${ }^{(4)}$

Iatrogenic trauma during urethral catheterization may result in either the formation of a false passage or urethral stricture disease. ${ }^{(5)}$ Such trauma is rare, with an overall incidence of $0.3 \%$. Personnel education programs have been shown to reduce iatrogenic injury by $78 \%{ }^{(6)}$ Traumatic cleaving and sphincteric disruption can be avoided by preventing catheter traction or by conversion to suprapubic cystostomy. ${ }^{(7)}$

The most frequent symptoms described after an aberrantly placed Foley catheter are pain and blocked catheter or urine leakage around the catheter. ${ }^{(3)}$ In our cases, both patients presented with pain as the primary symptom. Other symptoms are fever, partial or complete ureteric rupture, or incidental diagnosis. ${ }^{(8-10)}$

Ultrasound imaging of the bladder can be performed as a first method to confirm the location of the catheter and its balloon, but the technique of choice is CT to evaluate possible complications and the need for subsequent intervention. ${ }^{(8)}$ Ultrasound was not conclusive in our patients and CT was essential for making the diagnosis.

Patients that do not present with ureteric injury can be managed conservatively, by changing or removing the catheter and treating any urinary tract infection with antibiotics, ${ }^{(3)}$ as in our two cases. Patients with ureteric rupture require urinary diversion through ureteric stent insertion or percutaneous nephrostomy. Surgical repair is indicated for severe ureteric injury or in the case of ureteric rupture. ${ }^{(9)}$

The most expected sequel to the misplacement of a urinary catheter into the ureter is ureteral stricture, ${ }^{(3)}$, which did not occur in either of our cases. The patient with ureteral reflux was diagnosed with upper urinary tract carcinoma in the same ureter, through an incident-free ureterorenoscopy, whereas the other patient continued to have indwelling urinary catheters and uneventful replacements.

\section{Conclusion}

Catheterization is an invasive procedure that can cause embarrassment, as well as physical and psychological discomfort, and have a negative impact on the patient's self-image. The procedure has potential complications, so it must be performed by qualified personnel. Inadvertent urinary catheter placement in the ureter is rare, but it must be contemplated due to the serious complications it can involve.

\section{Conflict of interest}

None declared. 


\section{References}

1. Lowthian $\mathbf{P}$. The dangers of long-term catheter drainage. Br J Nurs. 1998;7(7):366-8, 370, 372 passim.

2. Niël-Weise BS, van den Broek PJ, da Silva EMK, Silva LA. Urinary catheter policies for long-term bladder drainage. Cochrane Database Syst Rev. 2012;(8):CD004201. doi: 10.1002/14651858. CD004201.pub3

3. Luo R, Lee SL, Ng FC, Koh L-T. Inadvertent placement of a urinary catheter into the ureter: A report of 3 cases and review of the literature. Asian J Urol. 2017;4(4):256-61. doi: 10.1016/j. ajur.2016.08.011

4. Parkin J, Scanlan J, Woolley M, Grover D, Evans A, Feneley RCL. Urinary catheter 'deflation cuff' formation: clinical audit and quantitative in vitro analysis. BJU Int. 2002;90(7):666-71. doi: 10.1046/j.1464-410x.2002.03014.x

5. Vaidyanathan S, Soni BM, Hughes PL, Singh G, Oo T. Severe ventral erosion of penis caused by indwelling urethral catheter and inflation of Foley balloon in urethra-need to create list of 'never events in spinal cord injury' in order to prevent these complications from happening in paraplegic and tetraplegic patients. Adv Urol. 2010;461539. doi: 10.1155/2010/461539
6. Kashefi C, Messer K, Barden R, Sexton C, Parsons JK. Incidence and prevention of iatrogenic urethral injuries. $J$ Urol. 2008;179(6):2254-7; discussion 2257-2258. doi: 10.1016/j.juro.2008.01.108

7. Lumen N, Hoebeke P, Willemsen P, De Troyer B, Pieters R, Oosterlinck W. Etiology of urethral stricture disease in the 21st century. J Urol. 2009;182(3):983-7. doi: 10.1016/j. juro.2009.05.023

8. Baker KS, Dane B, Edelstein Y, Malhotra A, Gould E. Ureteral rupture from aberrant Foley catheter placement: A case report. J Radiol Case Rep. 2013;7(1):33-40. doi: 10.3941/jrcr. v7i1.1276

9. Hale N, Baugh D, Womack G. Mid-ureteral rupture: a rare complication of urethral catheterization. Urology. 2012;80(5):e65-66. doi: 10.1016/j.urology.2012.07.011

10. Muneer A, Minhas S, Harrison SCW. Aberrant Foley catheter placement into the proximal right ureter. BJU International. 2002;89(7):795-795. doi: 10.1046/j.1464-410X.2002.t01-7-02801.x 